\title{
Altered cortical Cytoarchitecture in the Fmr1 knockout mouse
}

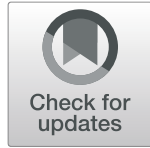

Frankie H. F. Lee ${ }^{1}$, Terence K. Y. Lai ${ }^{1,2}$, Ping Su ${ }^{1}$ and Fang Liu ${ }^{1,2,3^{*}}$ (D)

\begin{abstract}
Fragile X syndrome (FXS) is a neurodevelopmental disorder caused by silencing of the FMR1 gene and subsequent loss of its protein product, fragile $X$ retardation protein (FMRP). One of the most robust neuropathological findings in post-mortem human FXS and Fmr1 KO mice is the abnormal increase in dendritic spine densities, with the majority of spines showing an elongated immature morphology. However, the exact mechanisms of how FMRP can regulate dendritic spine development are still unclear. Abnormal dendritic spines can result from disturbances of multiple factors during neurodevelopment, such as alterations in neuron numbers, position and glial cells. In this study, we undertook a comprehensive histological analysis of the cerebral cortex in Fmr1 KO mice. They displayed significantly fewer neuron and PV-interneuron numbers, along with altered cortical lamination patterns. In terms of glial cells, Fmr1 $\mathrm{KO}$ mice exhibited an increase in Olig2-oligodendrocytes, which corresponded to the abnormally higher myelin expression in the corpus callosum. Iba1-microglia were significantly reduced but GFAP-astrocyte numbers and intensity were elevated. Using primary astrocytes derived from $\mathrm{KO}$ mice, we further demonstrated the presence of astrogliosis characterized by an increase in GFAP expression and astrocyte hypertrophy. Our findings provide important information on the cortical architecture of Fmr $\mathrm{KO}$ mice, and insights towards possible mechanisms associated with FXS.
\end{abstract}

Keywords: Fragile X syndrome, Fmr1 KO mice, Cortical architecture, Astrocytes

\section{Introduction}

Fragile X syndrome (FXS) is the most common inherited form of intellectual disability and one of the leading genetic causes of autism spectrum disorder (ASD), affecting approximately 1 in 4000 males and 1 in 6000 females [1-3]. It is characterized by a wide spectrum of clinical symptoms, including mild to severe intellectual disability, susceptibility to seizures, hyperactivity, hypersensitivity to sensory stimuli, autistic behaviors such as social anxiety and attention deficits, macroorchidism and abnormal facial features (Reviewed in [3]). FXS is a neurodevelopmental disorder caused by a CGG repeat expansion in the X-linked fragile $\mathrm{X}$ mental retardation 1 (FMR1) gene, which results in the transcriptional silencing of FMR1, and subsequent

\footnotetext{
* Correspondence: fang.liu@camh.ca

${ }^{1}$ Campbell Family Mental Health Research Institute, Centre for Addiction and Mental Health, Toronto, Ontario M5T 1R8, Canada

${ }^{2}$ Department of Physiology, University of Toronto, Toronto, Ontario M5T 1R8, Canada

Full list of author information is available at the end of the article
}

reduction of its protein product, fragile $\mathrm{X}$ retardation protein (FMRP) $[4,5]$.

FMR1 and FMRP are ubiquitously expressed in the mammalian CNS, beginning in early embryogenesis and persisting throughout development into adulthood [6]. At the cellular level, they are detected in different cell populations from proliferating cells of the developing brain, and later within pyramidal neurons, to GABAergic interneurons and glial cells of microglia, oligodendrocytes and astrocytes [6-11]. Functionally, FMRP regulates mRNA expression by binding and then suppressing the translation of its target mRNAs [3]. Genome-wide microarrays and high-throughput sequencing studies have identified more than 800 mRNA targets of FMRP, many of which are linked to neurodevelopmental processes including neurite growth, spine development, synaptic function and neuronal signaling [12-14]. The broad expression of FMRP in multiple cell types and brain regions, together with the vast number of interacting mRNA targets,

(c) The Author(s). 2019 Open Access This article is distributed under the terms of the Creative Commons Attribution 4.0 International License (http://creativecommons.org/licenses/by/4.0/), which permits unrestricted use, distribution, and reproduction in any medium, provided you give appropriate credit to the original author(s) and the source, provide a link to the Creative Commons license, and indicate if changes were made. The Creative Commons Public Domain Dedication waiver (http://creativecommons.org/publicdomain/zero/1.0/) applies to the data made available in this article, unless otherwise stated. 
suggest that it is immensely important for brain development and maturation.

Animal models are crucial in understanding the biological functions of genetic mutations. The Fmr1 knockout (KO) mouse, containing the loss of a functional FMRP protein, has been well-established in displaying behavioral abnormalities reminiscent of human FXS traits $[15,16]$. More importantly, many studies have since been using this model as a tool to investigate the pathophysiological mechanisms underlying FXS. One of the most robust neuropathological findings in post-mortem human FXS and Fmr1 KO mice is the abnormal increase in dendritic spine densities, with the majority of spines showing an elongated immature morphology [17-19]. However, evidence of other histological defects associated with FXS are still lacking, and inconsistent results have been described on neurotransmission properties, such as NMDA and AMPA receptor expression/function [3].

Dendritic spine development is a complicated process beginning with synaptogenesis in early childhood, synapse elimination/pruning in adolescence and spine maintenance in adulthood [20]. Proper development and maturation requires strict spatial and temporal regulation, involving multiple factors at each stage. Therefore, alterations in spine number and/or morphology could emerge from secondary effects or compensatory responses of any dysfunctional events occurring during that period. For example, neuron and interneuron numbers, cortical lamination pattern, and axonal connections and myelination have all been shown to affect spinogenesis [21-23]. Besides, recent evidence has directed microglia and astrocytes as key players in modulating synaptic formation and pruning via distinct pathways. For example, microglia and astrocytes mediate synapse elimination by direct engulfment of synapses through the complement system and MEGF10/MERTK respectively $[24,25]$. Moreover, alterations in cytokine production and astrocyte-specific glutamate transporters can have pronounced effects on dendritic spines [26-28].

Despite extensive research focusing on the functional role of FMRP in FXS, how it regulates spine development remains unclear. In this study, we undertook a comprehensive histological analysis of the cerebral cortex in the Fmr1 KO mice. They displayed reductions in cortical neuron and PV-interneuron numbers, along with altered cortical lamination patterns. In terms of glial cells, KO mutants exhibited distinct changes in Olig2-oligodendrocyte, Iba-1 microglia and GFAPastrocyte numbers. Using primary astrocytes from Fmr1 $\mathrm{KO}$ mice, we further demonstrated the presence of astrogliosis characterized by the significant increase in GFAP expression and astrocyte hypertrophy. Our findings provide important information on the cortical architecture of Fmr1 KO mice, and insights towards possible mechanisms that could be responsible for the increase in spine densities associated with FXS.

\section{Results}

Fewer neuron and parvalbumin (PV)-interneuron numbers in the Fmr $1 \mathrm{KO}$ mouse cortex

FMRP is strongly expressed in both pyramidal and GABAergic neurons from embryonic development to adulthood $[6,11]$, indicating that it is likely to play a role in their maturation and functions. First, we examined the number of neurons across the neocortex in the cingulate, motor and somatosensory regions of Fmrl $\mathrm{KO}$ mice (Fig. 1a). NeuN-immunolabeling of neurons revealed a significant reduction within the cingulate cortex of $\mathrm{KO}$ mice (WT: $1945 \pm 188$ cells per $\mathrm{mm}^{2}$; KO: $1777 \pm 144$ cells per $\mathrm{mm}^{2}$ ) but not the motor or somatosensory regions (Fig. 1bf). NeuN labels both pyramidal neurons and interneurons in the cortex [29], and since interneurons only comprise of approximately $20-30 \%$ of all cortical neurons [30], there is a possibility that the results may mask any differences in interneuron numbers. Hence we immunolabeled parvalbumin (PV), which is the most common interneuron subtype responsible for fast-spiking activity [31]. Total number PVcells were significantly fewer in the neocortex of $\mathrm{KO} \mathrm{mu-}$ tants when compared to WT (WT: $198 \pm 45$ cells per $\mathrm{mm}^{2}$; KO: $144 \pm 44$ cells per $\mathrm{mm}^{2}$ ) (Fig. $1 \mathrm{~g}, \mathrm{~h}$ ).

\section{Fmr1 KO mice show altered cortical lamination}

Next, we analyzed the effects of FMRP knockout on cortical neuronal positioning by performing immunohistochemistry with Cux1, a layer II/III-specific protein marker, and Ctip2, a layer V-marker [32]. To quantify the positions of Cux1- and Ctip2-labeled cells, a rectangular region of interest spanning the whole cortical layers I-VI was positioned over the neocortical region of fluorescentlabeled cells, and further subdivided into eight equal bins (Fig. 2a) [33]. The percentage of Cux1-labeled cells was significantly fewer in bin 3 near superficial layers II/III for $\mathrm{KO}$ mice relative to WT, but displayed a corresponding increase in deeper layers of bins 5, 6, 7 and 8 (Fig. 2b). These results indicate that neurons destined for superficial layers did not reach their correct location in the $\mathrm{KO} \mathrm{mu}-$ tants. As for Ctip2, there was a larger proportion of cells positioned in bin 3 for $\mathrm{KO}$ groups, but a lower proportion was observed in deeper layers of bin 5 (Fig. 2c). Together, our data suggest an aberrant localization of cortical neurons in the Fmr1 KO mice.

\section{Distinct changes in glial cell numbers of $F m r 1 \mathrm{KO}$ mice}

There is evidence indicating the presence of FMRP in glial cells of oligodendrocytes, microglia and astrocytes during early and mid-postnatal developmental stages of brain maturation $[6,7,10]$, which imply possible FMRP regulatory functions in these cell types. Hence we investigated the 


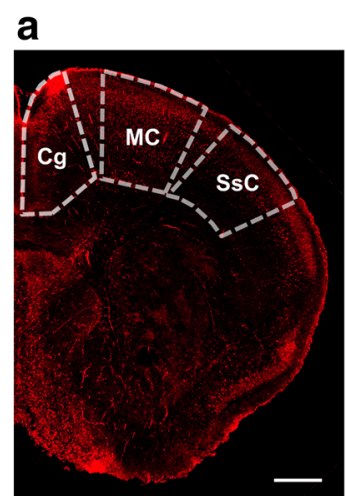

C

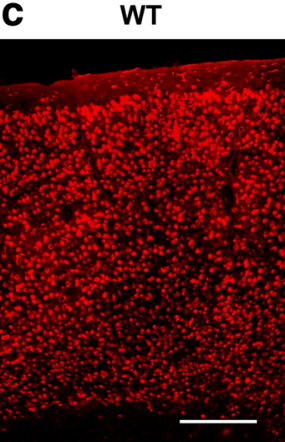

f

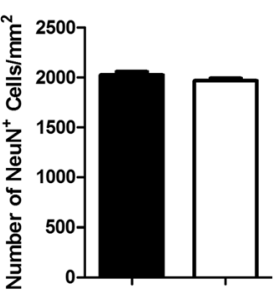

Motor Cortex b

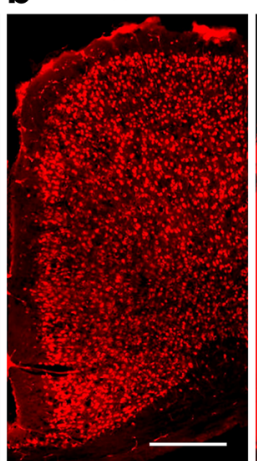

Fmr1KO

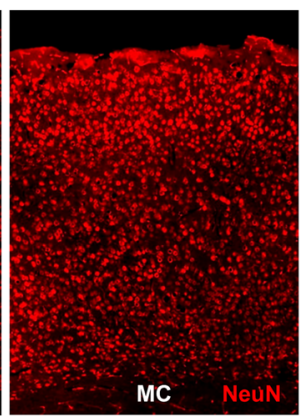

d
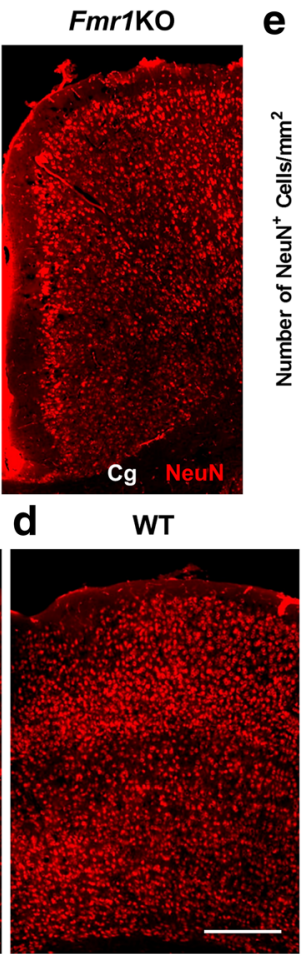

e

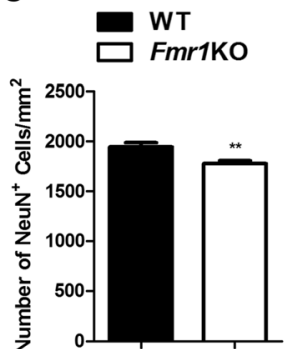

Cingulate Cortex

Fmr1KO

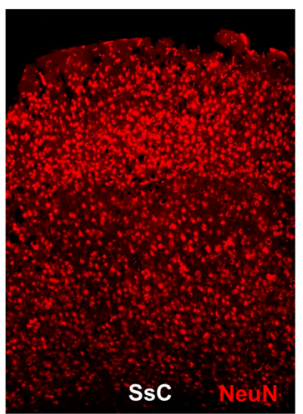

g
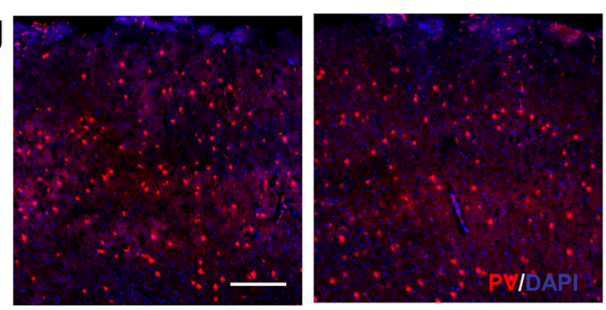

h

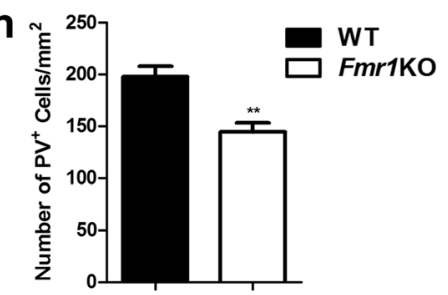

Fig. 1 Fewer neuron and parvalbumin (PV)-interneuron numbers in the Fmr1 KO mouse cortex. a Representative fluorescent images of NeuNimmunostained cells outlining the regions of interest across the neocortex, which includes the cingulate, motor and somatosensory cortex in WT and Fmr1 KO mice. Scale Bar: 300 mm. b-d Higher magnification images for each region are correspondingly shown. Scale Bar: 100 um. e, $\mathbf{f}$ The number of NeuN-positive cells in the cingulate cortex of KO mice is significantly lower than WT, but not the motor or somatosensory regions ( $n=24$ per group). $\mathbf{g}$, $\mathbf{h}$ Immunolabeling of parvalbumin (PV) shows that Fmrl KO mice also have less PV-interneurons in the neocortex when compared to WT ( $n=20-24$ per group). Scale Bar: $100 \mu \mathrm{m}$. Data are presented as mean \pm SEM. ${ }^{* *} p<0.01$. Cg: cingulate cortex, MC: motor cortex, SsC: somatosensory cortex

histological features of oligodendrocytes, microglia and astrocytes in the Fmr1 KO mouse cortex. Immunostaining of Olig2, a marker of pre-myelinating oligodendrocytes, resulted in a significant increase in oligodendrocyte numbers within the cortex, but not the corpus callosum of $\mathrm{KO}$ mice when compared to WT (WT: $381 \pm 110$ cells per $\mathrm{mm}^{2}$; KO: $499 \pm 190$ cells per $\mathrm{mm}^{2}$ ) (Fig. 3a-e). Since the primary function of oligodendrocytes is to myelinate axons which enables faster propagation of nerve impulses in the central nervous system (CNS), we further analyzed myelin expression in the medial and lateral corpus callosum (Fig. 3f). Using fluoromyelin-green, we observed a higher fluorescent intensity of myelin only in the medial part (WT: $45.48 \pm$ 10.95; KO: $55.48 \pm 7.81$ ). However, there was no difference within the lateral region of each hemisphere (Fig. 3g). The abnormal increase in cortical pre-myelinating oligodendrocytes may be responsible for the enhanced myelination observed in the medial corpus callosum. 


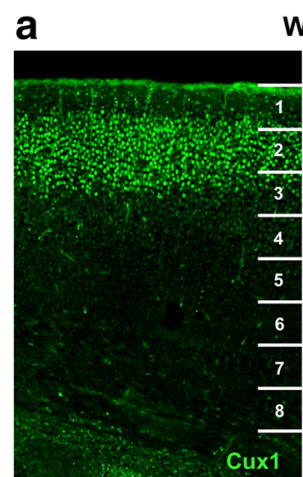

WT
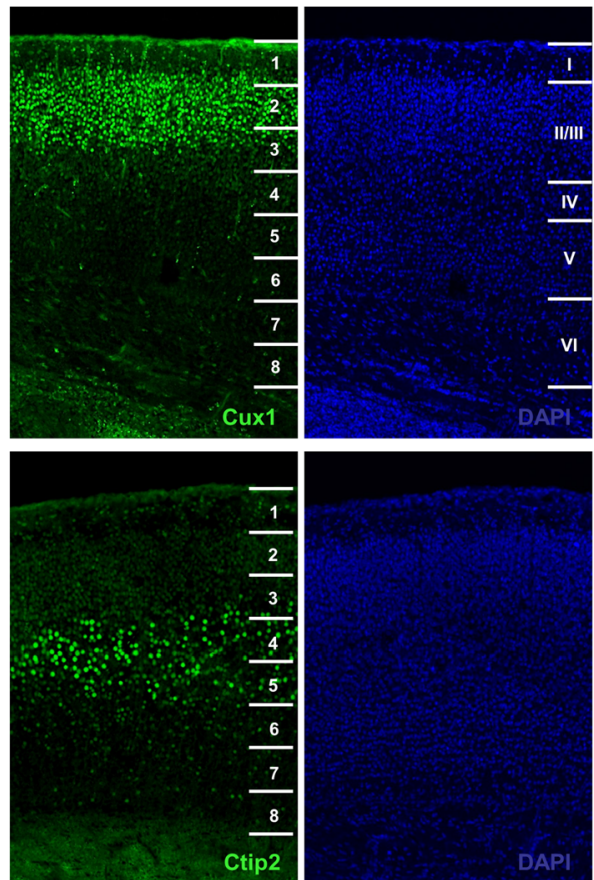

b

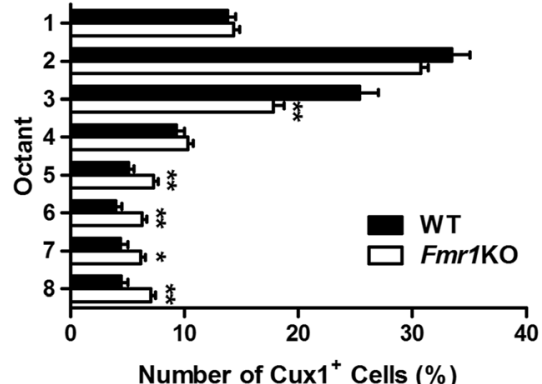

Fmr1KO
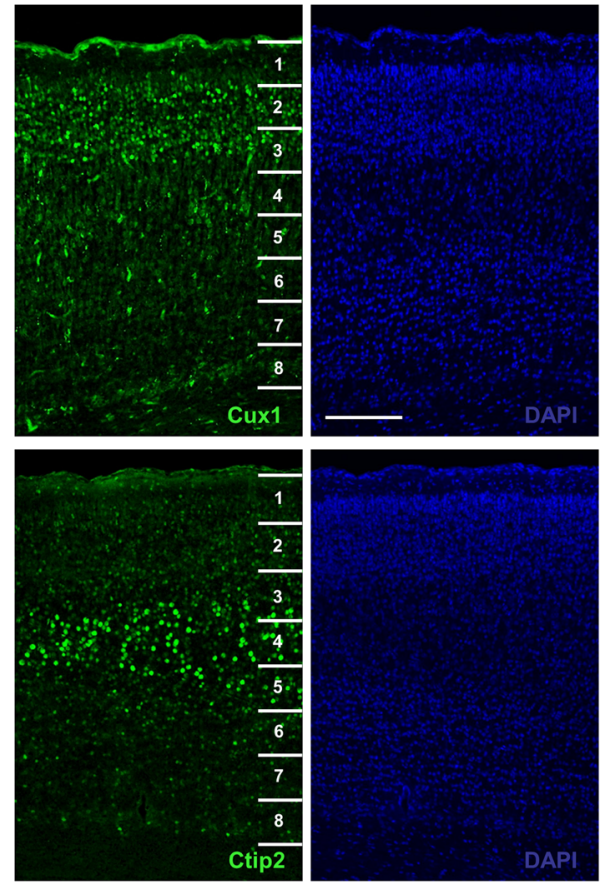

C

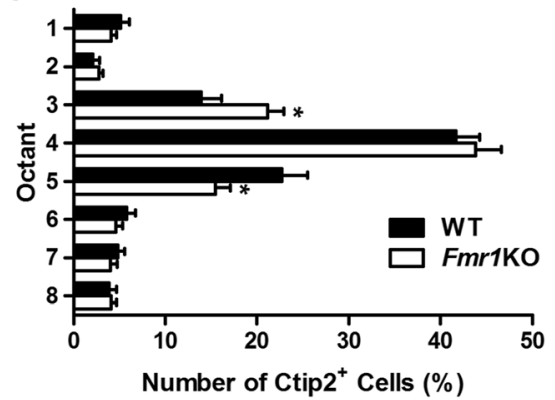

Fig. 2 Alterations of cortical neuronal distribution in Fmr1 KO mice. a Immunohistochemistry with Cux1, a layer II/II-specific protein marker, and Ctip2, a layer V-marker is performed in WT and Fmr $\mathrm{KO}$ mice. Regions of interest (ROIs) are positioned over the neocortex with each ROI further subdivided into eight equal bins spanning the pia to the inner border of the cortex, to assess neuron distribution in different cortical layers. The number of Cux ${ }^{+}$and Ctip2 $^{+}$cells are counted in each bin and expressed as a percentage total numbers. Scale Bar: $100 \mu \mathrm{m}$. b The proportion of Cux1-labeled cells is significantly lower in bin 3 near superficial layers II/II, along with a corresponding increase in deeper layers of bins 5, 6, 7 and 8 for KO mice relative to WT ( $n=24-32$ per group). c As for Ctip2, there is a larger proportion of cells positioned in bin 3 but less in deeper layer bin 5 of $\mathrm{KO}$ mutants when compared to controls ( $n=30-32$ per group). Data are presented as mean \pm SEM. ${ }^{*} p<0.05,{ }^{*} p<0.01$

In addition, we performed immunohistochemistry with anti-Iba1, a marker of microglia and anti-GFAP, a marker of astrocytes in WT and Fmr1 KO mice. The number of Iba1-positive microglia was significantly lower in the cortex of KO groups vs. WT (WT: $282 \pm 91$ cells per $\mathrm{mm}^{2}$; KO: $248 \pm 49$ cells per $\mathrm{mm}^{2}$ ) (Fig. $4 \mathrm{a}$, b). In contrast, Fmr1 KO mice exhibited more GFAPimmunoreactive astrocyte numbers (WT: $398 \pm 76$ cells per $\mathrm{mm}^{2}$; KO: $524 \pm 169$ cells per $\mathrm{mm}^{2}$ ), as well as higher GFAP fluorescent intensities (WT: $10.04 \pm 1.68$; KO: $12.73 \pm 2.92$ ) (Fig. 4c, d). It appears that FMRP deletion reduced the number of activated microglia, but promoted the state of astrogliosis. Together, our results demonstrated distinct alterations in the number of different glial cell types and in specific cortical regions.

\section{FMRP-depleted astrocytes exhibit a more pronounced} reactive state with higher GFAP expression and hypertrophy

To further address the direct effects of FMRP ablation on astrocytes reactivity, we prepared primary astrocyte cultures from neonatal cortical tissues of WT and Fmr1 $\mathrm{KO}$ brains. First, the lack of FMRP protein in astrocytes was confirmed in the $\mathrm{KO}$ group using immunocytochemistry and Western blot (Additional file 1: Figure S1a, b). Astrogliosis is characterized by profound 

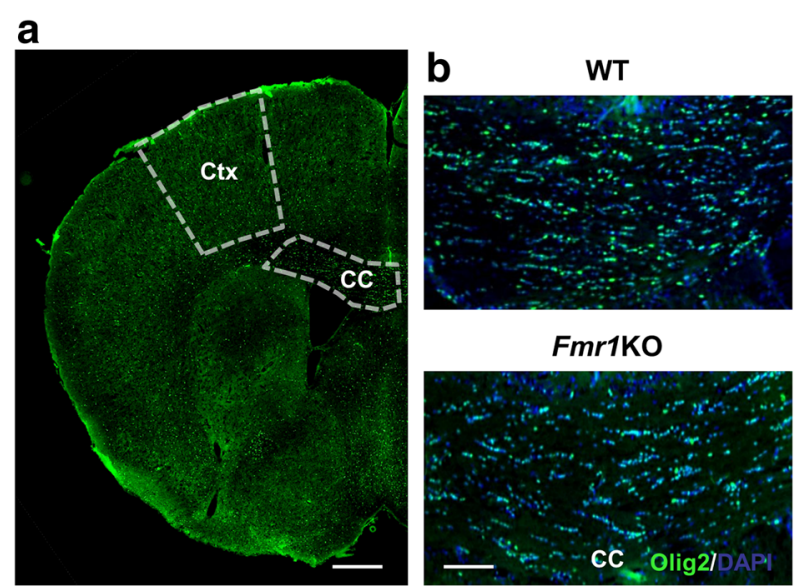

\section{d}
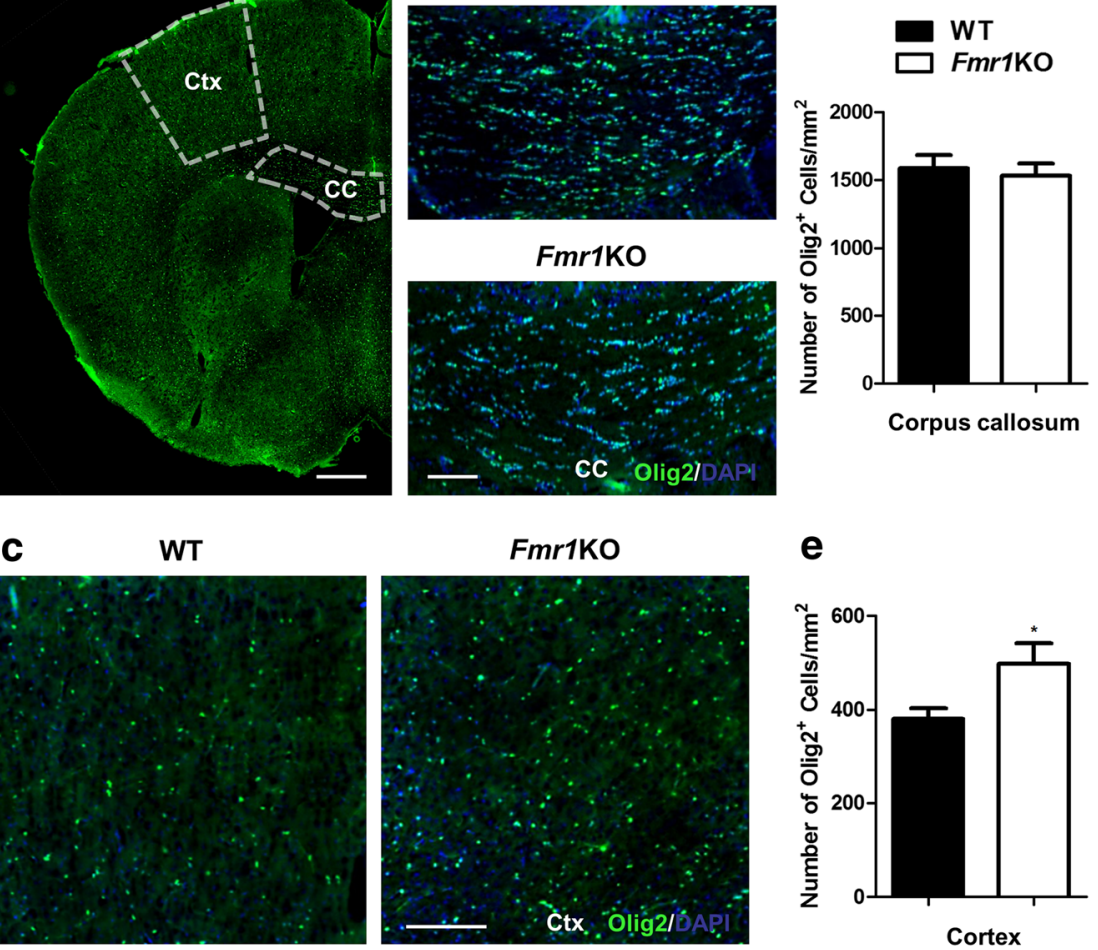

\section{e}

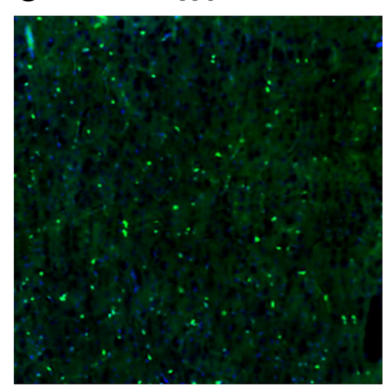

f
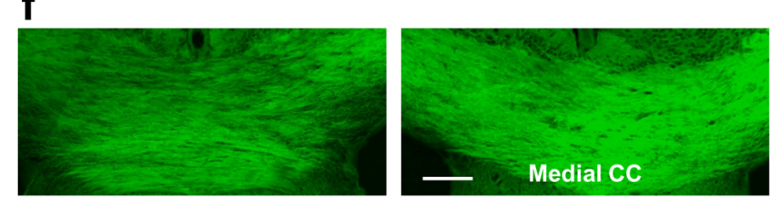

Fluoromyelin
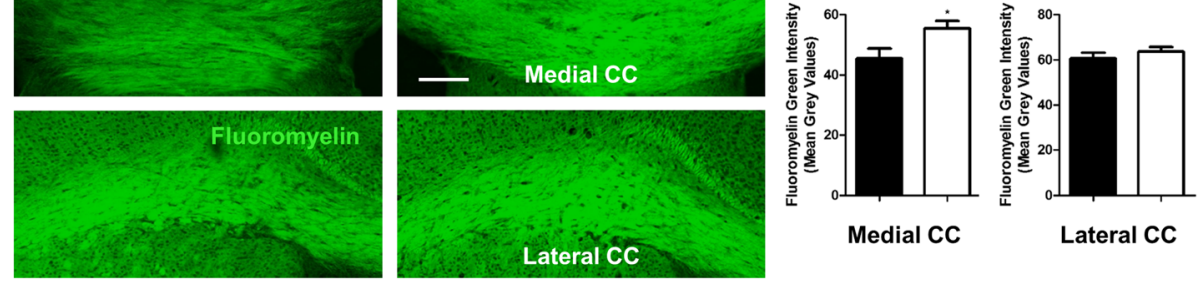

Fig. 3 Fmr1 KO mice show significantly more oligodendrocytes and enhanced myelination in the cortex. a Representative fluorescent images of Olig2

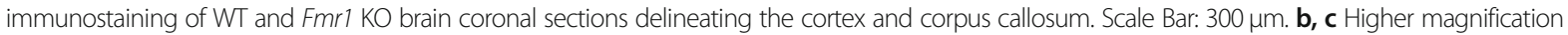
images of corpus callosum and cortex are shown. $\mathbf{d}$, e Compared to WT, KO mice have significantly more Olig2-positive pre-myelinating oligodendrocytes in the cortex but no difference is observed in the corpus callosum ( $n=20-24$ per group). $\mathbf{f}$ Fluoromyelin green was used to label myelin tracts in the medial and lateral part of the corpus callosum. $\mathbf{g}$ Likewise, myelin intensity is increased within the medial region but not the lateral sides of KO mutants ( $n=14-16$ per group). Scale Bar: $100 \mu \mathrm{m}$. Data are presented as mean \pm SEM. ${ }^{*} p<0.05$. Ctx: cortex, CC: corpus callosum

molecular and morphological changes in astrocytes in response to CNS injuries and diseases. These include a marked increase in GFAP expression and morphologically, astrocytes undergo extensive hypertrophy and proliferation [34, 35]. At the individual cell level, Fmr1 KO astrocytes displayed a profound increase in GFAP intensity (WT: $7.82 \pm 1.88$; KO: $16.28 \pm 4.71$ ) and astrocyte GFAP surface area (WT: $7647 \pm 2834 \mu \mathrm{m}^{2}$; KO: $14014 \pm$ $5553 \mu^{2}$ ) (Fig. 5a, b). Western blot analysis also validated the enhanced GFAP expression in astrocyte cultures of $\mathrm{KO}$ mutants (Fig. 5c). Actin reorganization has been shown to be a main determinant of cellular morphology, which is responsible for the morphological changes in reactive astrocytes. Indeed, evidence illustrating the loss and disassembly of F-actin fibres was found in different models of astrogliosis [36, 37]. As shown in Fig. 5d, we did not detect any loss of phalloidin-labeled F-actin fibres in Fmr1 KO astrocytes when compared to WT. However, marked alterations in the assembly of Factin were observed between the groups. Specifically, actin within normal astrocytes was detected to be more evenly distributed outlining the shape of each cell, but abnormal clusters were formed in the middle part of Fmr1 KO astrocytes (Fig. 5d). These findings suggest 
a
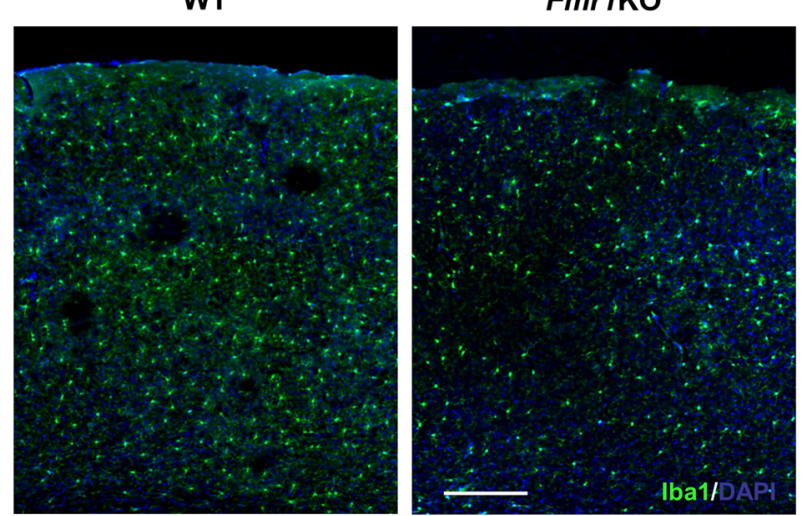

C
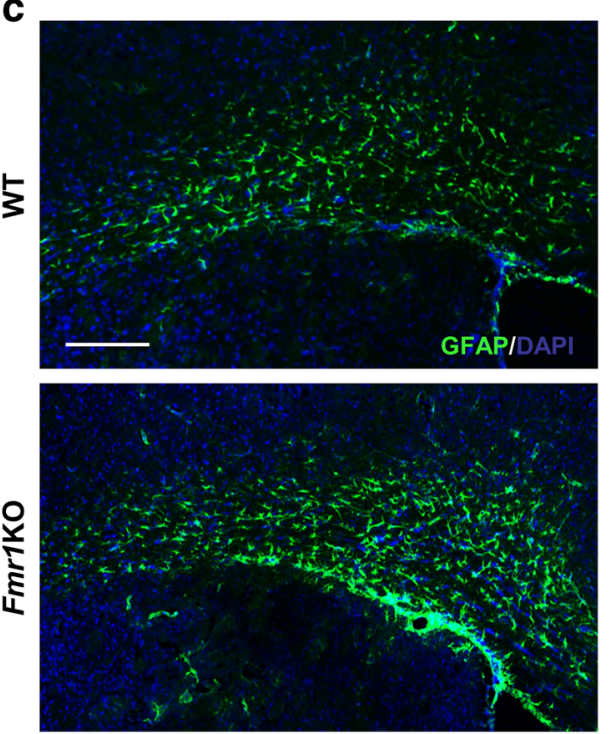

d

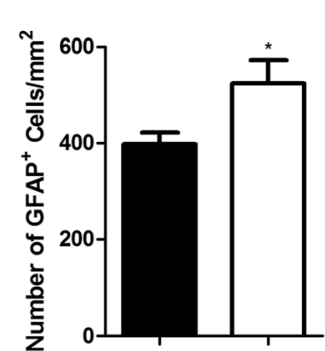

b
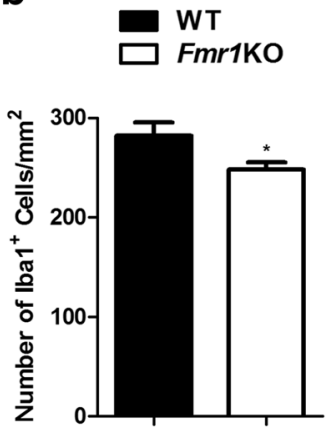
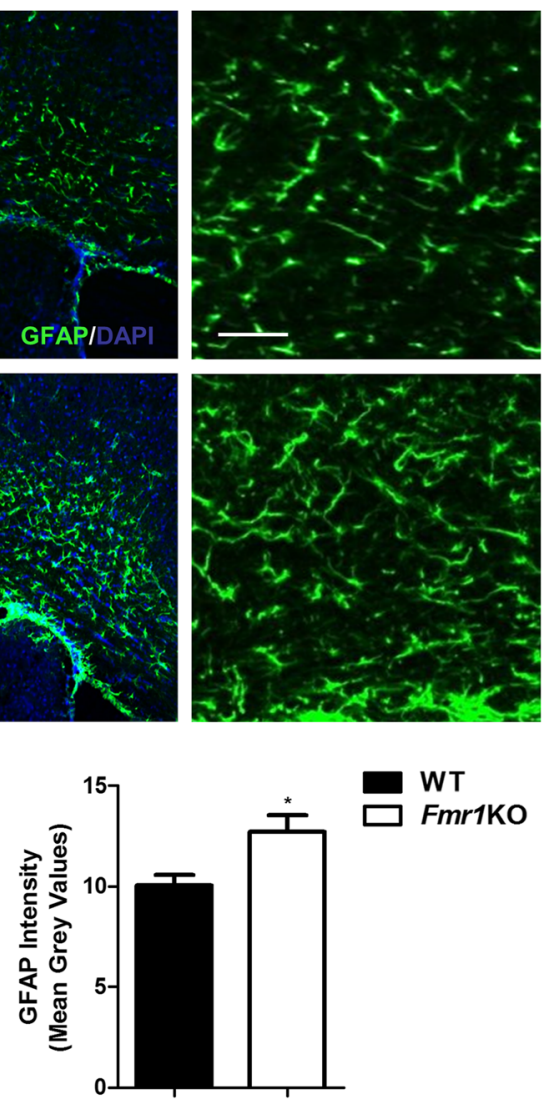

Fig. 4 Fmrl KO mice have less Iba1-positive microglia but more GFAP-astrocytes. a WT and Fmr1 KO mouse cortices are immunostained with Iba1 for microglia analysis. Scale Bar: $100 \mu \mathrm{m}$. b Quantification of Iba1-positive cells reveals fewer numbers in Fmr1 KO mutants ( $n=46-48$ per group). c Anti-GFAP is used to label astrocytes in the corpus callosum. Scale Bar: $100 \mu \mathrm{m}$. Higher magnification images are shown on the right. Scale Bar: $50 \mu \mathrm{m}$. $\mathbf{d}$ Fmr $1 \mathrm{KO}$ mutants have substantially more GFAP-astrocytes and higher GFAP expression ( $n=14-16$ per group). Data are presented as mean \pm SEM. ${ }^{*} p<0.05$

that abolishing FMRP results in astrogliosis, which may contribute to improper synaptic pruning and aberrant spine numbers.

\section{Discussion}

There is strong evidence indicating the diverse roles of FMRP in regulating many essential neurodevelopmental processes [3]. The most robust histopathological finding in FXS patients and Fmr1 KO mice is the abnormal increase in immature dendritic spine numbers [17-19]. However, the mechanisms of how FMRP can modulate spine development are still unclear. Disturbances in many neurodevelopmental factors can have profound effects on dendritic spines. In this study, we examined the cortical cytoarchitecture in the Fmr1 KO mouse cortex that could be associated with spine abnormalities. 
a

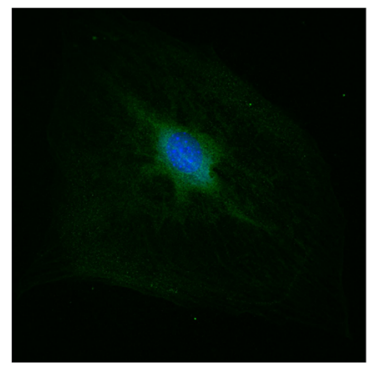

b

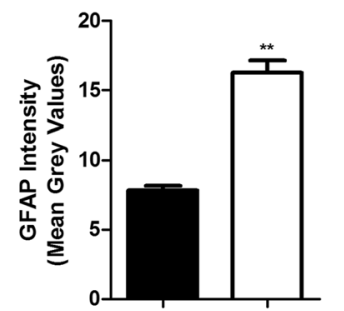

d
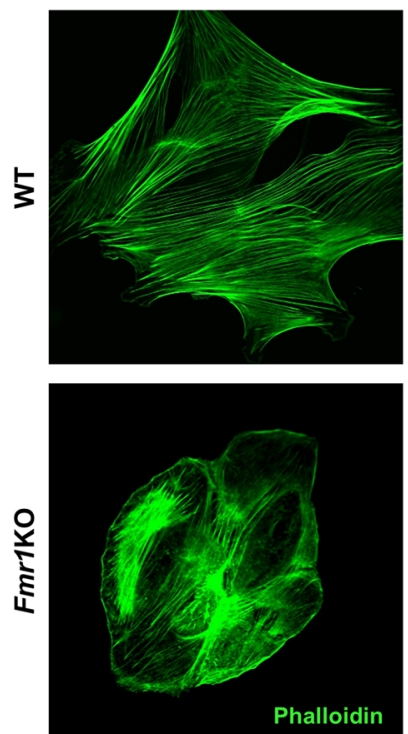
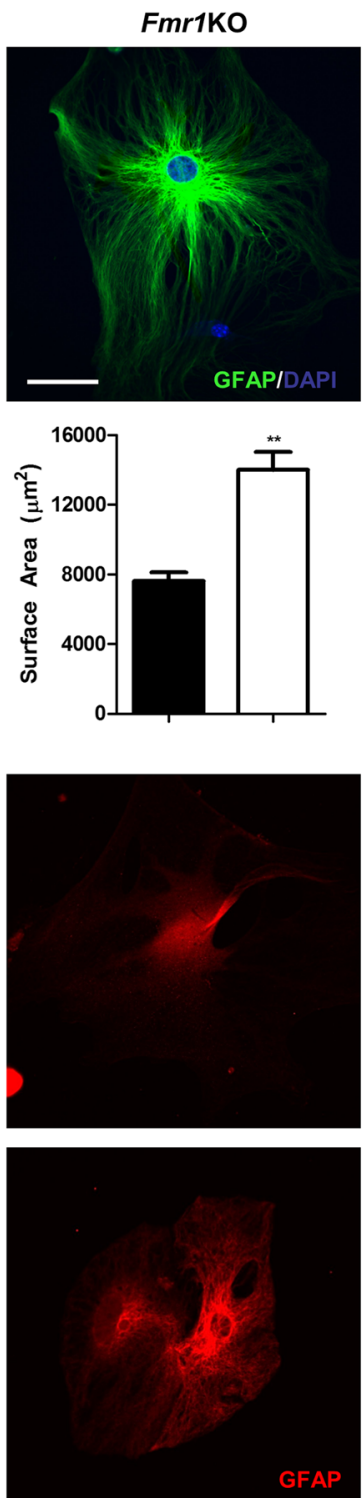

C
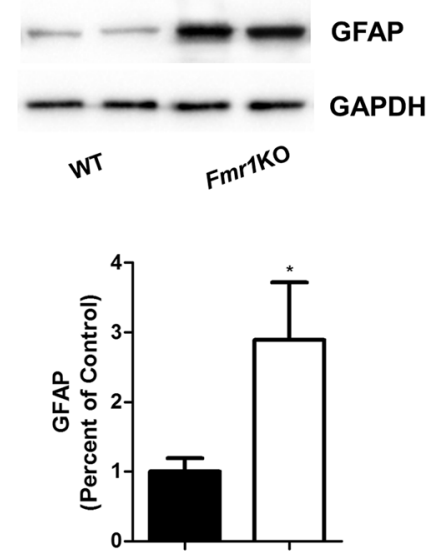

WT

$\square$ Fmr1Ko
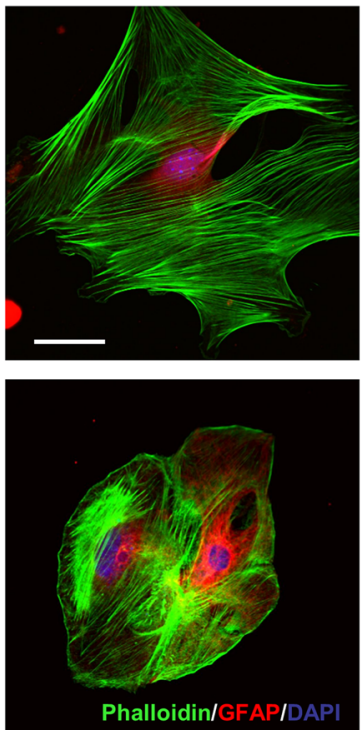

Fig. 5 FMRP-deficient astrocytes become reactive and display actin reorganization. a Primary astrocyte cultures derived from WT and Fmr $1 \mathrm{KO}$ neonatal brains are immunostained with GFAP. b KO-astrocytes have a pronounced increase in GFAP fluorescent intensity and astrocyte surface area, which are characteristics of reactive astrogliosis ( $n=30-34$ per group). c Western blot analysis confirms that GFAP expression is substantially higher in Fmrl KO astrocytes ( $n=4$ different cultures per group). d Representative fluorescent images showing F-actin fibres (labeled with phalloidin) in GFAPastrocyte cultures. Normal astrocytes display a distinct well-organized evenly distributed pattern, but F-actin in FMRP-depleted astrocytes form clusters in the cytoplasmic region. Scale Bar: $20 \mu \mathrm{m}$. Data are presented as mean \pm SEM. ${ }^{*} p<0.05,{ }^{* *} p<0.01$

Alterations in neuronal number and positioning can affect proper spine formation. There is evidence suggesting that neuronal populations inherently respond to lower neuronal densities by increasing the number of synapses [23]. We observed a small but significant decrease in neuronal density only within the cingulate cortex of $\mathrm{KO}$ mutants but not the lateral regions of motor and somatosensory cortex. Consistently, Hall et al. reported that patients with FXS had reduced gray matter density in the cingulate cortex using voxel-based morphometry [38]. In the Fmrl KO mouse, a study found no change in gross cortical neuronal morphology or overall cortical thickness of the primary somatosensory cortex [39]. Earlier studies have documented the involvement of FMRP in embryonic neurogenesis, where embryonic Fmr1 KO mice displayed accelerated neurogenesis, increased neuronal differentiation and enhanced accumulation of progenitors in the subventricular zone [40-42]. These newly differentiated FMRP-deficient neurons exhibit abnormal functional properties such as altered calcium responses and bursts activity [40, 43]. As a result, non-functional neurons that could not be integrated 
into the local circuitry are eliminated, which may explain the reduction in neuron number.

FMRP is also prominently expressed in GABAergic neuron populations, implying that it may have crucial roles in interneuron development and function $[8,11]$. Indeed, using the Fmr1 KO mouse model, many studies have illustrated defects in the inhibitory GABAergic circuitry [11, 44]. We found significantly fewer PVinterneurons in all regions across the neocortex, which was coherent with the results reported by Selby et al. [45]. Furthermore, according to Selby et al., this reduction mainly occurred in somatosensory cortical layers of II/III/IV, but not in deeper layers V and VI where PV numbers were increased [45]. These findings suggest that there could be differential histological deficits within cortical laminar organization. We noticed an aberrant cortical lamination pattern in the Fmr1 KO mutants compared to WT. Neurons destined for deeper layers were mis-positioned to superficial layers while those for superficial remained in deeper regions. Newborn neurons are established in an 'inside-out' pattern with the earliest born neurons forming the deep cortical layers, followed by later born neurons that progressively migrate into more superficial layers [32, 46, 47]. Our data corroborated with previous findings of more cortical neurons mis-positioned in deeper layers of Fmr1 $\mathrm{KO}$ embryonic brains, and further indicate that this effect persists into adulthood [48]. It is possible that FMRP deficiency may contribute to an accelerated neurogenesis in which more premature neurons are misdirected to deeper localization. Another explanation for neuronal mis-positioning in the cortex could be due to deficits in the migration process. Although some research have documented the role of FMRP in regulating neuronal migration [49-51], La Fata et al. reported that FMRP depletion did not affect radial migration of excitatory neurons [48]. A better understanding towards how FMRP modulates these processes associated with FXS is necessary. Nonetheless, this study provides a clearer histopathological perspective of neuron and interneuron numbers, and cortical laminar positioning in $F m r 1 \mathrm{KO}$ mice, as well as reflecting the possible neurodevelopmental processes affected by FMRP depletion.

FMRP expression is not only restricted to neuronal populations, but also present in developing and mature glial cells including oligodendrocytes, microglia and astrocytes $[6,7,10]$. Oligodendrocytes are primarily responsible for myelinating axons which enables faster and more efficient propagation of nerve impulses [52]. Hence, proper myelination is essential for normal neuronal development including dendritic spines [53]. Although different studies have indicated abnormal white matter structure in FXS patients and Fmr1 KO mice, the findings are still inconsistent [54]. We detected a pronounced increase in Olig2-positive pre-myelinating oligodendrocytes in the neocortex but not the corpus callosum of Fmr1 KO mice. Correspondingly, myelination only within the medial part of the corpus callosum was abnormally enhanced. In support of our results, a study found that oligodendrocyte ablation could lead to an increase in synapse numbers, possibly via modification of ionotropic glutamate receptors localization and function [55]. Both diffusion tensor imaging studies in FXS patients and magnetic resonance imaging studies in Fmr1 KO mice have shown an increase in white matter tract density $[56,57]$, despite others have reported reduced myelination patterns $[9,58]$. A more comprehensive study from Hall et al. suggested that white matter abnormalities associated with FXS are region-specific [54]. As the developmental origins of different brain regions are distinct, the functional role of FMRP on oligodendrocyte development and myelination may also differ. Moreover, there is evidence illustrating that FMRP can bind and regulate the translation of myelin basic protein (MBP) and CNPase (a myelin-associated enzyme) $[10,13]$. However, it remains unclear how FMRP modulate the different aspects of oligodendrocyte development, for instance the differentiation of oligodendrocyte precursor cells to mature oligodendrocytes, or apoptosis of oligodendrocytes. A more detail investigation on these events can provide important clues on the relationship between FMRP and white matter function associated with FXS.

Accumulating evidence strongly indicates that both microglia and astrocytes are involved in many neurodevelopmental processes, thus are immensely crucial in maintaining normal brain functions [59-61]. With regards to FXS, microglia can directly mediate dendritic spine elimination via the complement system where excessive synapses are tagged with complement proteins (C1q and C3) and consequently engulfed by microglial cells expressing complement receptors [24, 62, 63]. There is clinical evidence suggesting excessive microglial activation in multiple brains regions of patients with ASD [64, 65], but other studies did not detect any microglial activation or altered cytokine production in the Fmr1 KO mice [66, 67]. In our study, we found a slight reduction in the number of Iba1-positive cells across the neocortex of Fmr1 KO mutants, further justifying the absence of microglial activation. It is likely that the reduction in microglia leads to less synapse elimination mediated by the complement pathway [68], and other mediators such as IL-33 and CX3CR1s [69].

The importance of FMRP in astrocytes was validated by a recent study that showed astrocyte-specific FMRP knockout in mice resulted in increased spine density and behaviors reminiscent of FXS [70]. Astrocytes are a major source of complement $\mathrm{C} 3$, and therefore could 
participate in removing synapses by secreting C3 [68]. Similar to microglia, a study by Chung et al. described a direct phagocytic role of astrocytes on CNS synapses through phagocytic receptors, such as MEGF10 and MERTK [25]. In addition, astrocytes can also contribute to synaptic elimination via inositol 1,4,5-triphosphate receptor type 2 (IP3R2) and P2ry1 dependent signaling [71]. Here, we observed that Fmr1 KO mice exhibited prominent GFAP expression, while in vitro astrocyte cultures displayed hypertrophy and increased GFAP levels, all of which are hallmark features of reactive astrogliosis. In support of our findings, separate studies have provided evidence for astrocytic activation in the cerebellum of Fmr1 KO mouse [66, 67] and in patients with autism [65, 72]. Zamanian et al. conducted an extensive analysis on the genomic profile of reactive astrocytes, where they identified numerous genes of different signaling pathways were significantly induced [73]. FMRP-deficient reactive astrocytes are likely to exhibit similar alterations in gene expression that could contribute to the abnormal increase in dendritic spines. For instance, changes in genes of the complement pathway can affect the process of synapse tagging and removal [68]; and induction of cytokine production such as IL-6 is evidently linked to dendritic spine abnormalities as well as behaviors relevant to autism [26, 27]. Another possible mechanism can be attributed to the reduced expression of the astrocyte-specific glutamate transporter GLT1 in FMRP-deleted astrocytes, as selective reexpression of FMRP rescued abnormal spine morphology [28]. The detail mechanisms of how reactive astrogliosis in Fmr1 KO can cause an abnormal increase in dendritic spines would require more research on deciphering the downstream pathways.

In conclusion, we found that Fmr1 KO mice displayed histological deficits of fewer neuron and PV-interneuron numbers, altered cortical lamination, more Olig2oligodendrocytes with enhanced myelination expression, less Iba1-microglia and elevated GFAP expression and astrocyte numbers. Moreover, using primary astrocyte cultures from Fmr1 KO mouse cortex, we demonstrated the presence of astrogliosis characterized by pronounced GFAP expression and hypertrophy at the cellular level. These histopathological defects are strong indicators of perturbed neurodevelopmental processes that could either directly or indirectly contribute to the abnormal elevated spine numbers associated with FXS. Further studies on neurodevelopmental pathways such as neurogenesis, neuronal migration and glial development can address this question. More importantly, our results provide a starting point for future research in investigating at the specific pathways involved in dendritic spine formation and pruning, which could ultimately lead to novel treatments in FXS.

\begin{abstract}
Methods
Mice

Fmr1 KO mice on a C57/BL6J background were purchased from The Jackson Laboratory (B6.129P2$F m r 1^{\mathrm{tm} 1 \mathrm{Cgr}} / J$, Stock No: 003025), and bred at the Centre for Addiction and Mental Health (CAMH) (Toronto, Canada). Mice of approximately 4 weeks old were used for all experiments. Control groups were conducted with WT mice. All mouse protocols were approved by the CAMH Animal Care Committee and methods were carried out in accordance with the approved guidelines.
\end{abstract}

\section{Primary astrocyte culture preparation}

Cortical tissues from postnatal day 1-3 (P1-3) mouse brains were dissected out, incubated with $0.25 \%$ trypsin for $15 \mathrm{~min}$ at $37^{\circ} \mathrm{C}$, and dissociated by mechanical trituration. Cells were plated on T25 cell culture flasks, and grown in DMEM with $10 \%$ fetal bovine serum (FBS), $100 \mathrm{U} / \mathrm{ml}$ penicillin and $100 \mu \mathrm{g} / \mathrm{ml}$ streptomycin in an incubator $\left(37^{\circ} \mathrm{C}, 5 \% \mathrm{CO}_{2}\right)$ until astrocyte monolayers were confluent. Half of the DMEM was replaced every 3-4 days. To remove microglia and oligodendrocytes from mixed glial cultures, flasks were shaken for $24 \mathrm{~h}$ at $200 \mathrm{rpm}$ on an orbital shaker. Afterwards, versene solution and $2.5 \%$ trypsin were added to disaggregate astrocytes completely. Purified astrocytes were resuspended in DMEM/10\% FBS and plated on either glass coverslips or $60 \mathrm{~mm}$ culture dishes, and grown until approximately $50 \%$ confluency for immunocytochemistry or fully confluent for Western blot experiments. The purity of astrocytes was confirmed with GFAP/DAPI labeling.

\section{Immunofluorescence}

\section{Immunohistochemistry}

Adult mouse brains (approximately 8 weeks of age) were harvested, fixed in $4 \%$ paraformaldehyde (PFA) overnight, cryoprotected in $30 \%$ sucrose and frozen at $-80^{\circ} \mathrm{C}$ before further processing. $20 \mu \mathrm{m}$-thickness frozen coronal sections were cut using a microtome cryostat system (Leica CM3000). Free floating sections were initially blocked in $5 \%$ fetal bovine serum, $1 \%$ Triton X-100, $0.5 \%$ Tween 20 and $1 \%$ skim milk in $0.1 \mathrm{M}$ PBS for $2 \mathrm{~h}$ at room temperature to reduce non-specific binding. This was followed by incubation with primary antibodies overnight at $4{ }^{\circ} \mathrm{C}$ and secondary antibodies for $2 \mathrm{~h}$ in blocking solution at room temperature. The primary antibodies used in this study include: anti-NeuN (1:200, Millipore MAB377, Etobicoke, Canada), anti-Parvalbumin (1:200, SigmaAldrich P3088, Oakville, Canada), anti-CDP (M-222) (Cux1) (1:200, Santa Cruz Biotechnology sc-13,024, Dallas, TX, USA), anti-Ctip2 (1:200, Abcam ab28448, Cambridge, MS, USA), anti-Olig2 (1:200, Abcam ab109186), anti-Iba1 (1:500, Wako 019-19,741, Richmond, VA, USA) and anti-GFAP (1:200, Dako Z0334, Glostrup, Denmark). 
Alexa 488- or 594-conjugated secondary antibodies (1: 200; Thermo Fisher Scientific, Burlington, Canada) in blocking solution were used for detection of primary antibodies. Staining of myelin and nuclei was performed with Fluoromyelin green and DAPI (Thermo Fisher Scientific) respectively.

\section{Immunocytochemistry}

Astrocyte cultures were fixed in $4 \% \mathrm{PFA} / 4 \%$ sucrose, permeabilized with $0.1 \mathrm{M}$ PBS containing $0.1 \%$ Triton X100 for $15 \mathrm{~min}$, and blocked for $1 \mathrm{~h}$ with $1 \%$ bovine serum albumin in PBS at room temperature. Likewise, they were incubated with primary antibodies overnight at $4{ }^{\circ} \mathrm{C}$ and secondary antibodies for $1 \mathrm{~h}$ at room temperature. Primary antibodies used for this part include anti-GFAP (1:500; Dako Z0334) and anti-Fmrp (1: 200, Abcam ab17722). Alexa 488- phalloidin (Thermo Fisher Scientific A12379) and DAPI were also applied to label F-actin and nuclei respectively.

\section{Immunofluorescence analysis}

Fluorescent images of brain sections and astrocyte cultures were captured using a confocal microscope (Olympus FluoView FV1200) at either $10 \times$ or $60 \times$ magnification. For immunohistochemistry, slices chosen for analyses were anatomically-matched between comparing groups, and included samples from rostral to caudal regions. All images were converted to grey-scale and normalized to background staining. Fluorescently-labeled cells were quantified in specifically-defined regions of the cortex using the ITCN plugin for ImageJ (https://imagej.nih.gov/ ij/), where fixed parameters of cell width and threshold are pre-set such that only cells reaching the minimum signal will be counted. For Cux1 and Ctip2, regions of interest (ROIs) were positioned over cortical regions with each ROI further subdivided into eight equal bins from the pia to the inner border of the cortex, to assess neuron distribution across the layers of the cortex (Fig. 2a) [33]. The distribution was expressed as a percentage of the numbers of labeled-cells in each bin divided by the total numbers within each ROI [33]. In addition, fluorescent signal intensities of myelin staining and GFAP immunoreactivity were measured by mean grey values (ImageJ). Similarly with immunocytochemistry on astrocytes, the cell perimeter was first outlined and mean grey values of GFAP fluorescence, as well as surface area were determined as previously described. All image-capturing and threshold parameters were kept the same for each measurement between comparing groups.

\section{Western blot}

Proteins were first extracted from primary astrocyte cultures using RIPA buffer $(50 \mathrm{mM}$ Tris- $\mathrm{HCl} \mathrm{pH} 7.4,150$ $\mathrm{mM} \mathrm{NaCl}, 2 \mathrm{mM}$ EDTA, $1 \mathrm{mM}$ PMSF with $1 \%$ Igepal
CA-630, 1\% sodium deoxycholate, $1 \%$ Triton X-100 and protease inhibitor cocktail (1:100, Sigma P8340), followed by BCA protein assay (Thermo Fisher Scientific $23,225)$ to determine the concentration of each sample. $100 \mu \mathrm{g}$ of solubilized proteins were boiled in Laemmli sample buffer for $5 \mathrm{~min}$, subjected to sodium dodecyl sulfate (SDS)-polyacrylamide gel electrophoresis, and subsequently transferred onto nitrocellulose membranes. The blots were incubated with primary antibodies of anti-GFAP (Dako Z0334), anti-Fmrp (Abcam ab17722) and anti-GAPDH (Millipore MAB374) overnight at $4{ }^{\circ} \mathrm{C}$, then with horseradish peroxidase-conjugated secondary antibodies for $2 \mathrm{~h}$ at room temperature. Protein bands were visualized with enhanced chemiluminescence reagents (Amersham Biosciences, Buckinghamshire, UK). The intensity of all resulting bands was quantified by densitometry using ImageJ, normalized to loading bands (GAPDH) and expressed as a percentage of WT controls. Triplicates were performed for each sample.

\section{Statistical analysis}

The Student's two-tailed $t$-test was performed to determine statistical differences between WT and Fmr1 KO groups. Neuronal distributions of Cux1 and Ctip2 were analyzed with the one-way ANOVA (GraphPad 5.0), with Bonferroni's correction for multiple testing. All images were blinded prior to analysis. Data were expressed as mean \pm standard error of mean (SEM) and a significance level of $p<0.05$ was used.

\section{Additional file}

Additional file 1: Absence of FMRP in primary astrocytes derived from Fmrl KO mice. (PPT $585 \mathrm{~kb}$ )

Abbreviations

ASD: Autism Spectrum Disorder; CNS: Central Nervous System; FMR1: Fragile X Mental Retardation 1; FMRP: Fragile X Mental Retardation Protein;

FXS: Fragile X Syndrome; GFAP: Glial Fibrillary Acidic Protein; KO: Knockout; MBP: Myelin Basic Protein; PV: Parvalbumin; WT: Wildtype

\section{Publisher's Note}

Springer Nature remains neutral with regard to jurisdictional claims in published maps and institutional affiliations.

\section{Acknowledgements \\ Not applicable.}

Authors' contributions

FHFL and FL designed the study. FHFL prepared all cells and brain tissues, performed all immunofluorescent experiments, image acquisition, data analysis and manuscript writing. FHFL and TKYL performed Western blots and data analysis. PS helped with breeding and maintaining Fmr1 KO mouse colony. FL supervised all projects and contributed in writing the manuscript. All authors read and approved the final manuscript.

Funding

Not applicable. 


\section{Availability of data and materials}

The datasets used and/or analysed during the current study are available from the corresponding author on reasonable request.

\section{Ethics approval and consent to participate} Not applicable.

\section{Consent for publication}

Not applicable.

\section{Competing interests}

The authors declare that they have no competing interests.

\section{Author details}

${ }^{1}$ Campbell Family Mental Health Research Institute, Centre for Addiction and Mental Health, Toronto, Ontario M5T 1R8, Canada. ${ }^{2}$ Department of Physiology, University of Toronto, Toronto, Ontario M5T 1R8, Canada. ${ }^{3}$ Department of Psychiatry, University of Toronto, Toronto, Ontario M5T 1R8, Canada.

Received: 10 April 2019 Accepted: 3 June 2019

Published online: 14 June 2019

\section{References}

1. Harris SW, HessI D, Goodlin-Jones B, Ferranti J, Bacalman S, Barbato I, et al. Autism profiles of males with fragile X syndrome. Am J Ment Retard. 2008; 113(6):427-38.

2. Rogers SJ, Wehner DE, Hagerman R. The behavioral phenotype in fragile $X$ : symptoms of autism in very young children with fragile $X$ syndrome, idiopathic autism, and other developmental disorders. J Dev Behav Pediatr. 2001;22(6):409-17.

3. Sethna F, Moon C, Wang H. From FMRP function to potential therapies for fragile X syndrome. Neurochem Res. 2014;39(6):1016-31.

4. Pieretti M, Zhang FP, Fu YH, Warren ST, Oostra BA, Caskey CT, et al. Absence of expression of the FMR-1 gene in fragile X syndrome. Cell. 1991;66(4):817-22.

5. Sutcliffe JS, Nelson DL, Zhang F, Pieretti M, Caskey CT, Saxe D, et al. DNA methylation represses FMR-1 transcription in fragile $X$ syndrome. Hum Mol Genet. 1992;1(6):397-400.

6. Gholizadeh S, Halder SK, Hampson DR. Expression of fragile X mental retardation protein in neurons and glia of the developing and adult mouse brain. Brain Res. 2015;1596:22-30.

7. Pacey LK, Doering LC. Developmental expression of FMRP in the astrocyte lineage: implications for fragile X syndrome. Glia. 2007;55(15):1601-9.

8. Olmos-Serrano JL, Paluszkiewicz SM, Martin BS, Kaufmann WE, Corbin JG, Huntsman MM. Defective GABAergic neurotransmission and pharmacological rescue of neuronal hyperexcitability in the amygdala in a mouse model of fragile X syndrome. J Neurosci. 2010;30(29):9929-38.

9. Pacey LK, Xuan IC, Guan S, Sussman D, Henkelman RM, Chen Y, et al. Delayed myelination in a mouse model of fragile $X$ syndrome. Hum Mol Genet. 2013;22(19):3920-30.

10. Wang H, Ku L, Osterhout DJ, Li W, Ahmadian A, Liang Z, et al. Developmentally-programmed FMRP expression in oligodendrocytes: a potential role of FMRP in regulating translation in oligodendroglia progenitors. Hum Mol Genet. 2004;13(1):79-89.

11. Paluszkiewicz SM, Martin BS, Huntsman MM. Fragile $X$ syndrome: the GABAergic system and circuit dysfunction. Dev Neurosci. 2011;33(5):349-64.

12. Brown V, Jin P, Ceman S, Darnell JC, O'Donnell WT, Tenenbaum SA, et al. Microarray identification of FMRP-associated brain mRNAs and altered mRNA translational profiles in fragile $X$ syndrome. Cell. 2001;107(4):477-87.

13. Darnell JC, Van Driesche SJ, Zhang C, Hung KY, Mele A, Fraser CE, et al. FMRP stalls ribosomal translocation on mRNAs linked to synaptic function and autism. Cell. 2011;146(2):247-61.

14. Ascano M Jr, Mukherjee N, Bandaru P, Miller JB, Nusbaum JD, Corcoran DL, et al. FMRP targets distinct mRNA sequence elements to regulate protein expression. Nature. 2012;492(7429):382-6.

15. Kazdoba TM, Leach PT, Silverman JL, Crawley JN. Modeling fragile $X$ syndrome in the Fmr1 knockout mouse. Intractable Rare Dis Res. 2014;3(4):118-33.

16. The Dutch-Belgian Fragile X Consortium, Bakker CE, Verheij C, Willemsen $R$, van der Helm R, Oerlemans F, et al. Fmr 1 knockout mice: a model to study fragile X mental retardation. Cell. 1994;78(1):23-33.
17. Nimchinsky EA, Oberlander AM, Svoboda K. Abnormal development of dendritic spines in FMR1 knock-out mice. J Neurosci. 2001;21(14):5139-46.

18. Comery TA, Harris JB, Willems PJ, Oostra BA, Irwin SA, Weiler IJ, et al. Abnormal dendritic spines in fragile $X$ knockout mice: maturation and pruning deficits. Proc Natl Acad Sci U S A. 1997;94(10):5401-4.

19. He CX, Portera-Cailliau C. The trouble with spines in fragile $X$ syndrome: density, maturity and plasticity. Neuroscience. 2013;251:120-8.

20. Penzes P, Cahill ME, Jones KA, VanLeeuwen JE, Woolfrey KM. Dendritic spine pathology in neuropsychiatric disorders. Nat Neurosci. 2011;14(3):285-93.

21. Hoistad M, Segal D, Takahashi N, Sakurai T, Buxbaum JD, Hof PR. Linking white and grey matter in schizophrenia: oligodendrocyte and neuron pathology in the prefrontal cortex. Front Neuroanat. 2009;3:9.

22. Garcia-Lopez P, Garcia-Marin V, Freire M. Dendritic spines and development: towards a unifying model of spinogenesis--a present day review of Cajal's histological slides and drawings. Neural Plast. 2010;2010:769207.

23. Cullen DK, Gilroy ME, Irons HR, Laplaca MC. Synapse-to-neuron ratio is inversely related to neuronal density in mature neuronal cultures. Brain Res. 2010;1359:44-55.

24. Stephan AH, Barres BA, Stevens B. The complement system: an unexpected role in synaptic pruning during development and disease. Annu Rev Neurosci. 2012:35:369-89.

25. Chung WS, Clarke LE, Wang GX, Stafford BK, Sher A, Chakraborty C, et al. Astrocytes mediate synapse elimination through MEGF10 and MERTK pathways. Nature. 2013;504(7480):394-400.

26. Wei H, Chadman KK, McCloskey DP, Sheikh AM, Malik M, Brown WT, et al. Brain IL-6 elevation causes neuronal circuitry imbalances and mediates autism-like behaviors. Biochim Biophys Acta. 2012;1822(6):831-42.

27. Krasovska $V$, Doering LC. Regulation of IL- 6 secretion by astrocytes via TLR4 in the fragile X mouse model. Front Mol Neurosci. 2018;11:272.

28. Higashimori H, Schin CS, Chiang MS, Morel L, Shoneye TA, Nelson DL, et al. Selective deletion of Astroglial FMRP dysregulates glutamate transporter GLT1 and contributes to fragile X syndrome phenotypes in vivo. J Neurosci. 2016;36(27):7079-94.

29. Wolf HK, Buslei R, Schmidt-Kastner R, Schmidt-Kastner PK, Pietsch T, Wiestler OD, et al. NeuN: a useful neuronal marker for diagnostic histopathology. J Histochem Cytochem. 1996;44(10):1167-71.

30. Markram H, Toledo-Rodriguez M, Wang Y, Gupta A, Silberberg G, Wu C. Interneurons of the neocortical inhibitory system. Nat Rev Neurosci. 2004; 5(10):793-807.

31. Kawaguchi Y, Kubota Y. Correlation of physiological subgroupings of nonpyramidal cells with parvalbumin- and calbindinD28k-immunoreactive neurons in layer $\vee$ of rat frontal cortex. J Neurophysiol. 1993;70(1):387-96.

32. Molyneaux BJ, Arlotta P, Menezes JR, Macklis JD. Neuronal subtype specification in the cerebral cortex. Nat Rev Neurosci. 2007;8(6):427-37.

33. Lee FH, Fadel MP, Preston-Maher K, Cordes SP, Clapcote SJ, Price DJ, et al. Disc1 point mutations in mice affect development of the cerebral cortex. J Neurosci. 2011;31(9):3197-206.

34. Pekny M, Nilsson M. Astrocyte activation and reactive gliosis. Glia. 2005; 50(4):427-34.

35. Sofroniew MV. Molecular dissection of reactive astrogliosis and glial scar formation. Trends Neurosci. 2009:32(12):638-47.

36. Berretta A, Gowing EK, Jasoni CL, Clarkson AN. Sonic hedgehog stimulates neurite outgrowth in a mechanical stretch model of reactive-astrogliosis. Sci Rep. 2016;6:21896

37. John GR, Chen L, Rivieccio MA, Melendez-Vasquez CV, Hartley A, Brosnan CF. Interleukin-1 beta induces a reactive astroglial phenotype via deactivation of the rho GTPase-rock axis. J Neurosci. 2004;24(11):2837-45.

38. Hall SS, Jiang H, Reiss AL, Greicius MD. Identifying large-scale brain networks in fragile X syndrome. JAMA Psychiatry. 2013;70(11):1215-23.

39. Till SM, Wijetunge LS, Seidel VG, Harlow E, Wright AK, Bagni C, et al. Altered maturation of the primary somatosensory cortex in a mouse model of fragile X syndrome. Hum Mol Genet. 2012;21(10):2143-56.

40. Castren M, Tervonen $\mathrm{T}$, Karkkainen V, Heinonen $\mathrm{S}$, Castren $\mathrm{E}$, Larsson $\mathrm{K}$, et al. Altered differentiation of neural stem cells in fragile $X$ syndrome. Proc Natl Acad Sci U S A. 2005;102(49):17834-9.

41. Tervonen TA, Louhivuori $V$, Sun X, Hokkanen ME, Kratochwil CF, Zebryk P, et al. Aberrant differentiation of glutamatergic cells in neocortex of mouse model for fragile X syndrome. Neurobiol Dis. 2009:33(2):250-9.

42. Khalfallah O, Jarjat M, Davidovic L, Nottet N, Cestele S, Mantegazza M, et al. Depletion of the fragile $X$ mental retardation protein in embryonic stem cells alters the kinetics of neurogenesis. Stem Cells. 2017;35(2):374-85. 
43. Sunamura N, Iwashita S, Enomoto K, Kadoshima T, Isono F. Loss of the fragile $X$ mental retardation protein causes aberrant differentiation in human neural progenitor cells. Sci Rep. 2018;8(1):11585.

44. Cea-Del Rio CA, Huntsman MM. The contribution of inhibitory interneurons to circuit dysfunction in fragile X syndrome. Front Cell Neurosci. 2014;8:245.

45. Selby L, Zhang C, Sun QQ. Major defects in neocortical GABAergic inhibitory circuits in mice lacking the fragile $X$ mental retardation protein. Neurosci Lett. 2007;412(3):227-32.

46. Rakic P. Neurons in rhesus monkey visual cortex: systematic relation between time of origin and eventual disposition. Science. 1974;183(4123):425-7.

47. Leone DP, Srinivasan K, Chen B, Alcamo E, McConnell SK. The determination of projection neuron identity in the developing cerebral cortex. Curr Opin Neurobiol. 2008;18(1):28-35.

48. La Fata G, Gartner A, Dominguez-Iturza N, Dresselaers T, Dawitz J, Poorthuis $\mathrm{RB}$, et al. FMRP regulates multipolar to bipolar transition affecting neuronal migration and cortical circuitry. Nat Neurosci. 2014;17(12):1693-700.

49. Moro F, Pisano T, Bernardina BD, Polli R, Murgia A, Zoccante L, et al. Periventricular heterotopia in fragile X syndrome. Neurology. 2006;67(4):713-5.

50. Achuta VS, Rezov V, Uutela M, Louhivuori V, Louhivuori L, Castren ML. Tissue plasminogen activator contributes to alterations of neuronal migration and activity-dependent responses in fragile X mice. J Neurosci. 2014:34(5):1916-23.

51. Castren ML. Cortical neurogenesis in fragile X syndrome. Front Biosci. 2016; 8:160-8.

52. Baumann N, Pham-Dinh D. Biology of oligodendrocyte and myelin in the mammalian central nervous system. Physiol Rev. 2001;81(2):871-927.

53. Tau GZ, Peterson BS. Normal development of brain circuits. Neuropsychopharmacology. 2010;35(1):147-68.

54. Hall SS, Dougherty RF, Reiss AL. Profiles of aberrant white matter microstructure in fragile X syndrome. Neurolmage Clinical. 2016;11:133-8.

55. Doretto S, Malerba M, Ramos M, Ikrar T, Kinoshita C, De Mei C, et al. Oligodendrocytes as regulators of neuronal networks during early postnatal development. PLoS One. 2011;6(5):e19849.

56. Haas BW, Barnea-Goraly N, Lightbody AA, Patnaik SS, Hoeft F, Hazlett H, et al. Early white-matter abnormalities of the ventral frontostriatal pathway in fragile X syndrome. Dev Med Child Neurol. 2009;51(8):593-9.

57. Lai JK, Lerch JP, Doering LC, Foster JA, Ellegood J. Regional brain volumes changes in adult male FMR1-KO mouse on the FVB strain. Neuroscience. 2016;318:12-21.

58. Barnea-Goraly N, Eliez S, Hedeus M, Menon V, White CD, Moseley M, et al. White matter tract alterations in fragile $X$ syndrome: preliminary evidence from diffusion tensor imaging. American journal of medical genetics part B, neuropsychiatric genetics: the official publication of the international society of. Psychiatr Genet. 2003;118B(1):81-8.

59. Sominsky L, De Luca S, Spencer SJ. Microglia: key players in neurodevelopment and neuronal plasticity. Int J Biochem Cell Biol. 2018;94:56-60.

60. Reemst K, Noctor SC, Lucassen PJ, Hol EM. The indispensable roles of microglia and astrocytes during brain development. Front Hum Neurosci. 2016;10:566.

61. Sloan SA, Barres BA. Mechanisms of astrocyte development and their contributions to neurodevelopmental disorders. Curr Opin Neurobiol. 2014; 27:75-81.

62. Paolicelli RC, Bolasco G, Pagani F, Maggi L, Scianni M, Panzanelli P, et al. Synaptic pruning by microglia is necessary for normal brain development. Science. 2011;333(6048):1456-8.

63. Stevens B, Allen NJ, Vazquez LE, Howell GR, Christopherson KS, Nouri N, et al. The classical complement cascade mediates CNS synapse elimination. Cell. 2007;131(6):1164-78.

64. Suzuki K, Sugihara G, Ouchi Y, Nakamura K, Futatsubashi M, Takebayashi K, et al. Microglial activation in young adults with autism spectrum disorder. JAMA Psychiatry. 2013;70(1):49-58.

65. Vargas DL, Nascimbene C, Krishnan C, Zimmerman AW, Pardo CA. Neuroglial activation and neuroinflammation in the brain of patients with autism. Ann Neurol. 2005;57(1):67-81.

66. Yuskaitis CJ, Beurel E, Jope RS. Evidence of reactive astrocytes but not peripheral immune system activation in a mouse model of fragile $X$ syndrome. Biochim Biophys Acta. 2010;1802(11):1006-12.

67. Pacey LK, Guan S, Tharmalingam S, Thomsen C, Hampson DR. Persistent astrocyte activation in the fragile X mouse cerebellum. Brain Behav. 2015; 5(10):e00400.

68. Lian $\mathrm{H}$, Litvinchuk $\mathrm{A}$, Chiang AC, Aithmitti N, Jankowsky JL, Zheng $\mathrm{H}$. Astrocyte-microglia cross talk through complement activation modulates amyloid pathology in mouse models of Alzheimer's disease. J Neurosci. 2016:36(2):577-89.

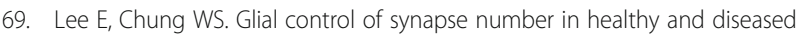
brain. Front Cell Neurosci. 2019;13:42.

70. Hodges JL, Yu X, Gilmore A, Bennett H, Tjia M, Perna JF, et al. Astrocytic contributions to synaptic and learning abnormalities in a mouse model of fragile $X$ syndrome. Biol Psychiatry. 2017;82(2):139-49.

71. Yang J, Yang H, Liu Y, Li X, Qin L, Lou H, et al. Astrocytes contribute to synapse elimination via type 2 inositol 1,4,5-trisphosphate receptordependent release of ATP. eLife. 2016;5:e15043.

72. Laurence JA, Fatemi SH. Glial fibrillary acidic protein is elevated in superior frontal, parietal and cerebellar cortices of autistic subjects. Cerebellum. 2005; 4(3):206-10.

73. Zamanian JL, Xu L, Foo LC, Nouri N, Zhou L, Giffard RG, et al. Genomic analysis of reactive astrogliosis. J Neurosci. 2012;32(18):6391-410.

\section{Publisher's Note}

Springer Nature remains neutral with regard to jurisdictional claims in published maps and institutional affiliations.

\section{Ready to submit your research? Choose BMC and benefit from:}

- fast, convenient online submission

- thorough peer review by experienced researchers in your field

- rapid publication on acceptance

- support for research data, including large and complex data types

- gold Open Access which fosters wider collaboration and increased citations

- maximum visibility for your research: over $100 \mathrm{M}$ website views per year

At $\mathrm{BMC}$, research is always in progress.

Learn more biomedcentral.com/submissions 